\title{
Under Recognized Aspects of the Predatory Journals
}

\author{
Afşin Emre Kayıpmaz, Cemil Kavalcı \\ Department of Emergency, Başkent University Faculty of Medicine, Ankara, Turkey
}

Dear Editor,

We read with interest the article entitled "A Growing Threat for Academicians: Fake and Predatory Journals" by Pamukçu Günaydın and Doğan published in your journal (Eurasian J Emerg Med 14(2): 94-6) (1). We would like to thank the authors for making a huge contribution to such an important subject of debate.

Universities' regulations for appointment or promotion to a lecturer, and the regulations for associate professor examinations issued by the Higher Education Council have pushed particularly young academicians towards publishing papers hastily. As the authors pointed, one of the greatest dangers in this process is the "predatory" journals. It is noted that predatory journals do not even comply with Basic English grammatical rules in their websites or e-mails, which should be an ominous sign for authors. Such journals also deceive readers and authors by using ostentatious titles for their names such as "American Journal of..." or "International Journal of...." Sometimes, these journals mimic the names of prestigious journals that have been not published for a considerable time or changed their names. These predatory journals typically mimic these journals publishing in languages that are not as widely used as English, such as Spanish, Portuguese, and German (Kasmera Journal, Sylwan Journal, etc). Some predatory journals also request high fees for accessing their archives. Requesting a fee for accessing its own archives is a suspicious circumstance in itself for a journal that claims open access publishing. In the case of two separate journals using the same title, being able to access previous issues of the original journal should guide for authors to prefer the right journal. Another important property of a predatory journal is that it accepts a paper without making any suggestions for changes to it since it is usually not a peer-reviewed journal (2). This may occasionally give rise to quite funny circumstances; for instance inclusion of Turkish phrases in an issue of a journal publishing in English.
While predatory journals involve such threats for young academicians, they are associated with an alternative hazard for senior academicians: editorship or membership of editorial boards. Hence, senior academicians should be cautious when accepting the requests of editorship or membership for editorial boards from such journals.

Trying to take advantage of the transformation of printed journals into electronic ones, such journals may have internet sites that can suddenly vanish (3).

In conclusion, academicians must be vigilant and cautious for predatory journals promising rapid reviewing and publishing for any paper. Instead of publishing in journals most of which are of Far East origin, the academicians should ideally prefer domestic journals indexed by international indexes. After inspecting the index page of a journal, the index claimed to index that journal should be accessed and this information should be verified. As of 22.06.2015, there are 363 journals indexed by the Turkish Citation Index (4). We suggest that rather than publishing in suspicious foreign journals, young academicians would better prefer these domestic journals which are also indexed in reputable international indexes.

\section{References}

1. Pamukçu Gunaydin GP, Dogan NO. A Growing Threat for Academicians: Fake and Predatory Journals. Eurasian J Emerg Med 2015; 14: 94-6. [CrossRef]

2. Bowman JD. Predatory Publishing, Questionable Peer Review, and Fraudulent. Am J Pharm Educ 2014; 78: 1-6. [CrossRef]

3. Kearney MH, The INANE Predatory Publishing Practices Collaborative. Predatory Publishing: What Authors Need to Know. Res Nurs Health 2015; 38: 1-3. [CrossRef]

4. List of journals indexed in Turkish Citation Index. [Internet] [Cited: 2015, June 22] Available from: URL: http://www.atifdizini.com/journals/tr-index.html. 